\title{
Perioperative monitoring in high-risk infants after stage 1 palliation of univentricular congenital heart disease
}

\author{
Nancy S. Ghanayem, MD, ${ }^{\text {a,c }}$ George M. Hoffman, MD, ${ }^{\text {a,c,d }}$ Kathleen A. Mussatto, PhD, RN, ${ }^{\text {a }}$

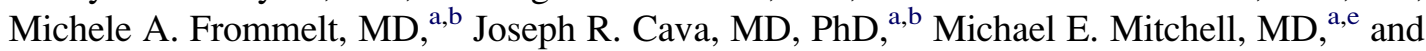 \\ James S. Tweddell, MD ${ }^{\mathrm{a}, \mathrm{e}}$
}

\begin{abstract}
Objective: Survival of high-risk patients with univentricular heart disease after Norwood palliation is reduced. We hypothesized that early goal-directed monitoring with venous oximetry and near-infrared spectroscopy would offset their increased vulnerability and improve survival.
\end{abstract}

\begin{abstract}
Methods: A prospective database of patients undergoing stage 1 palliation was used to assess differences in outcomes across risk groups in the setting of a comprehensive, goal-directed monitoring program. High-risk criteria included gestational age 35 weeks or less, birth weight less than $2.5 \mathrm{~kg}$, and additional cardiac or extracardiac anomalies. Outcomes included survival to defined end points and measures of postoperative support.
\end{abstract}

Results: From September 2000 to September 2008, 162 patients underwent stage 1 palliation: 28\% (45/162) high-risk and $72 \%(117 / 162)$ standard-risk patients. Lesions other than hypoplastic left heart syndrome were more common among high-risk patients $(38 \%, 17 / 45$, vs $15 \%, 18 / 117, P=.003)$. Operative survival was not statistically different $(87 \%, 39 / 45$, high risk vs $95 \%, 111 / 117$, standard risk, $P=.1)$. High-risk patients were more likely to receive inpatient treatment until stage 2 palliation $(24 \%, 11 / 45$, vs $10 \%, 12 / 117, P=.001)$ and had lower 1-year survival $(78 \%$ vs $93 \%, P=.01)$ and survival to date $(71 \%$ vs $92 \%, P=.001)$.

Conclusions: Intensive monitoring partially offset biologic vulnerability of high-risk patients, helping attain comparable early outcomes. Vulnerability persisted throughout the interstage period, however, and increased mortality beyond cavopulmonary shunt was seen only among high-risk patients. Although enhanced monitoring reduced early mortality, high resource use and attrition after stage 2 palliation suggest an ongoing need to evaluate our current palliative strategy for this subset of patients. (J Thorac Cardiovasc Surg 2010;140:857-63)

Patient-related factors, in addition to surgical technique and perioperative management strategies, influence outcomes after Norwood palliation for hypoplastic left heart syndrome (HLHS) and its variants. Recent studies have found worsened outcomes among patients with prematurity, low birth weight, extracardiac anomalies, or additional cardiac defects and have designated these patients as at high risk for standard staged palliation because of early perioperative mortality of $50 \%$ to $70 \%{ }^{1-5}$ As a result, some centers have developed alternative approaches for patients considered to be at high risk for Norwood palliation. ${ }^{6,7} \mathrm{We}$ and others have reported improved outcomes with perioperative monitoring strategies that include venous oximetry and near-infrared spectroscopy to guide interventions. ${ }^{8-13}$

\footnotetext{
From the Herma Heart Center at the Children's Hospital of Wisconsin ${ }^{\mathrm{a}}$ and the Divisions of Cardiology ${ }^{\mathrm{b}}$ and Critical Care ${ }^{\mathrm{c}}$ in the Department of Pediatrics, the Department of Anesthesia, ${ }^{\mathrm{d}}$ and the Division of Cardiothoracic Surgery in the Department of Surgery, ${ }^{\mathrm{e}}$ Medical College of Wisconsin, Milwaukee, Wis. Disclosures: None.

Received for publication May 13, 2009; revisions received April 19, 2010; accepted for publication May 9, 2010; available ahead of print July 12, 2010.

Address for reprints: Nancy S Ghanayem, MD, Children's Hospital of Wisconsin, 9000 W Wisconsin Ave, Milwaukee, WI 53226 (E-mail: nancyg@mcw.edu). $0022-5223 / \$ 36.00$

Copyright (C) 2010 by The American Association for Thoracic Surgery doi:10.1016/j.jtcvs.2010.05.002
}

There have been no studies addressing the efficacy of such an intensive monitoring strategy for subgroups of patients with HLHS. An intensive monitoring strategy may have greater value for the higher risk group; alternatively, that group may be too sick to benefit from such a strategy. We sought to address this question in this study and hypothesized that early goal-directed monitoring with venous oximetry and near-infrared spectroscopy would offset the increased vulnerability of these high-risk patients and improve their operative survival and survival to stage 2 palliation.

\section{MATERIALS AND METHODS \\ Patients}

This is an observational study from a human research review board-approved prospective database of 162 patients who underwent stage 1 palliation (S1P) for univentricular heart disease at Children's Hospital of Wisconsin from September 2000 to September 2008. This cohort was managed with a comprehensive monitoring program including postoperative venous oximetry and heightened interstage surveillance until bidirectional cavopulmonary shunt. Two-site near-infrared spectroscopic monitoring of regional perfusion was introduced in May 2002. Forty-five of the 162 patients $(28 \%)$ within this cohort were considered high-risk patients and had at least 1 of the following concomitant diagnoses: 35 weeks gestation or less, birth weight less than $2.5 \mathrm{~kg}$, additional cardiac anomalies, or extracardiac anomalies. High-risk patients were compared with 117 of 162 standard-risk patients $(72 \%)$. 


\section{Abbreviations and Acronyms \\ $\mathrm{ECMO}=$ extracorporeal membrane oxygenation \\ HLHS $=$ hypoplastic left heart syndrome \\ $\mathrm{S} 1 \mathrm{P}=$ stage 1 palliation \\ $\mathrm{SaO}_{2}=$ arterial oxygen saturation \\ $\mathrm{SrO}_{2}=$ regional tissue oxygen saturation \\ $\mathrm{SvO}_{2}=$ venous oxygen saturation}

\section{Intraoperative Management}

All patients within this cohort underwent S1P with either a modified Blalock-Taussig shunt or a right ventricle-pulmonary artery conduit. The right ventricle-pulmonary artery conduit was introduced as the provision for pulmonary blood flow in October 2003. Previously described surgical technique included relief of aortic arch obstruction by means of coarctectomy, augmentation of the aortic arch with allograft pulmonary artery, and sideto-side anastomosis of the aortic and pulmonary roots with a proximal cut back below the sinotubular ridge of the pulmonary root. ${ }^{14}$ All patients were supported with deep hypothermic cardiopulmonary bypass with antegrade cerebral perfusion through a shunt sewn on polytetrafluoroethylene graft anastomosed to the innominate artery. Brief circulatory arrest was used during the atrial septectomy in all cases and during arterial cannula repositioning in patients with modified Blalock-Taussig shunts. Modified ultrafiltration was used in all cases. Methylprednisolone $(10 \mathrm{mg} / \mathrm{kg})$ was routinely administered at 8 hours and 2 hours before surgery. Aprotinin $\left(1.7 \times 10^{6} \mathrm{KIU} / \mathrm{m}^{2}\right)$ was administered intravenously before skin incision, in the bypass circuit prime, and as a continuous infusion of $4.0 \times 10^{5}$ $\mathrm{KIU} /\left(\mathrm{m}^{2} \cdot \mathrm{h}\right)$ during the procedure in 154 consecutive patients. The most recent 8 patients who could not receive aprotinin received aminocaproic acid ( $75 \mathrm{mg} / \mathrm{kg}$ loading to the patient and to the circuit prime, followed by infusion at $75 \mathrm{mg} /[\mathrm{kg} \cdot \mathrm{h}]$ until surgery end $)$. Phenoxybenzamine $(0.25 \mathrm{mg} / \mathrm{kg})$ was added to the pump prime according to a human research review boardand Food and Drug Administration-approved protocol and investigational new drug exemption. Oximetric catheters were surgically placed in the superior vena cava before separation from cardiopulmonary bypass. ${ }^{15}$ Milrinone was initiated during rewarming, and epinephrine and norepinephrine were titrated during separation from bypass to achieve an approximate systemic vascular resistance index of 12 Wood units, adequate inotropy, and goal-directed end points. All patients underwent delayed sternal closure.

\section{Postoperative Management}

Standardized postoperative monitoring including continuous invasive arterial blood pressure, central venous pressure, arterial saturation $\left(\mathrm{SaO}_{2}\right.$; Masimo Corp, Irvine, Calif), and venous saturation $\left(\mathrm{SvO}_{2}\right.$; Abbott Laboratories, Abbott Park, Ill), with blood drawn from the superior vena cava was used for this cohort. In the most recent 129 patients, 2-site (cerebral and somatic) regional oximetry with near-infrared spectroscopy (INVOS 5100A; Somanetics Corporation, Troy, Mich) was used to assess regional tissue oxyhemoglobin saturation $\left(\mathrm{SrO}_{2}\right){ }^{15}$ Postoperative management targets were $\mathrm{SaO}_{2}$ greater than $75 \%, \mathrm{SvO}_{2}$ greater than $50 \%$, cerebral $\mathrm{Sro}_{2}$ greater than $50 \%$, somatic $\mathrm{SrO}_{2}$ greater than $60 \%$, mean arterial pressure greater than $45 \mathrm{~mm} \mathrm{Hg}$, diastolic blood pressure greater than $30 \mathrm{~mm} \mathrm{Hg}$, and atrial pressure less than $12 \mathrm{~mm} \mathrm{Hg}$.

\section{Interstage Management}

After S1P, patients discharged to home participated in an interstage monitoring program, with daily assessments of $\mathrm{SaO}_{2}$ and weight by parents until cavopulmonary shunt. $\mathrm{SaO}_{2}$ less than $75 \%$ at rest, weight loss, or failure to gain weight prompted investigation on either an outpatient or inpatient basis to rule out an intercurrent illness or an anatomic lesion as the etiology of the monitoring abnormality. ${ }^{8,11}$ Patients thought to be at increased risk for interstage mortality because of significant atrioventricular valve insufficiency, arrhythmias, or extracardiac concerns remained in the hospital until further surgical intervention.

\section{Timing of Bidirectional Cavopulmonary Shunt}

Current practice at Children's Hospital of Wisconsin includes elective cavopulmonary anastomosis between 4 and 5 months of age. Practice is based on analysis of trends in arterial oxygenation and growth in a cohort of home-monitored patients after S1P, with earlier progression to cavopulmonary anastomosis for patients found to have excessive hypoxemia, growth failure, or symptoms of progressive heart failure. ${ }^{11,16}$ Patients thought to be poor candidates for further single-ventricle palliation are listed for transplant.

\section{Data Analysis}

Early and intermediate outcomes compared between high-risk and standard-risk groups included operative mortality (defined as occurring within 30 days after surgery in or out of hospital or after 30 days during the same hospitalization), ability to achieve superior cavopulmonary anastomosis, 1-year survival, and survival to date. A perioperative hemodynamic database containing parameters prospectively acquired for 48 hours was used for hemodynamic comparison between groups. Continuously measured parameters included $\mathrm{SaO}_{2}$ (Masimo SET on GE Solar), $\mathrm{SvO}_{2}$ (4F Oxycath; Abbott), mean arterial pressure, heart rate, central venous pressure (transthoracic atrial line), frontal cerebral and T12-L2 somatic $\mathrm{SrO}_{2}$ values (Somanetics 5100B/C pediatric sensors), end-tidal $\mathrm{PCO}_{2}$ (Novametrix main stream CapnoStat/GE Solar; Respironics, Inc, Murrysville, Pa), and inspired oxygen fraction. Periodic measures included arterial hemoglobin concentration, arterial $\mathrm{PCO}_{2}$, arterial $\mathrm{Po}_{2}, \mathrm{pH}$, base excess interpolated to hourly measures, and vasoactive drug infusion rates. Derived variables included pulmonary to systemic flow ratio $\left(\left[\mathrm{SaO}_{2}-\mathrm{SvO}_{2}\right] /\left(97-\mathrm{SaO}_{2}\right.\right.$, assuming pulmonary capillary saturation of $97 \%$ ), arteriovenous oxygen content difference, systemic and pulmonary vascular resistance indices (assuming an oxygen consumption of $160 \mathrm{~mL} /\left[\mathrm{m}^{2} \cdot \mathrm{min}\right]$ ), and physiologic dead space ([arterial $\mathrm{PCO}_{2}-$ end-tidal $\left.\mathrm{PCO}_{2}\right]$ )/arterial $\left.\mathrm{PCO}_{2}\right)$. Need for extracorporeal membrane oxygenation (ECMO) after S1P, placement of enteral feeding tube, interstage management, age and weight at second-stage palliation, and transplant status were also compared between groups.

Data were expressed as mean \pm SD for continuous variables and as median with range or $5 \%$ to $95 \%$ confidence intervals when appropriate. Categoric variables are described as counts and percentages. High-risk versus standard risk patients were compared for categoric outcome variables with the $\chi^{2}$ statistic or Fisher's Exact test. The effect of imbalances in treatment factors between risk groups was corrected by propensity score matching and reported as the average effect attributable to the risk group. KaplanMeier actuarial survival analysis with log-rank comparison between groups was used to compare overall survival. The differences in mean values of hemodynamic parameters and support levels between high-risk and standard-risk groups were assessed by mixed-model time-series regression techniques. The cutoff for significance was $P<.05$ after multiple comparison correction with the Tukey honestly significant difference or the Bonferroni method, as applicable. All statistical analyses were performed with SPSS Version 17.0 (SPSS Inc, an IBM Company, Chicago, Ill) and Stata Version 10 (StataCorp LP, College Station, Tex).

\section{RESULTS}

From September 2000 through September 2008, a total of 162 patients underwent S1P. Operative survival for this cohort was $92 \%$. Survival to cavopulmonary shunt or interstage cardiac transplant (5 patients) was $91 \%$, survival to 1 year of age was $90 \%$, and survival to date was $86 \%$. Within 
TABLE 1. Additional diagnoses for high-risk group

\begin{tabular}{|c|c|}
\hline Diagnosis & No. \\
\hline Low birth weight $(\leq 2.5 \mathrm{~kg})$ & 15 \\
\hline Prematurity ( $\leq 35$ gestational wk) & 10 \\
\hline \multicolumn{2}{|l|}{ Additional cardiac anomalies } \\
\hline Anomalous venous drainage & \\
\hline Anomalous origin of coronary artery & \\
\hline Left atrial thrombus & \\
\hline Intact atrial septum & \\
\hline Congenital heart block & \\
\hline \multicolumn{2}{|l|}{ Extracardiac anomalies } \\
\hline \multicolumn{2}{|l|}{ Airway or respiratory } \\
\hline \multicolumn{2}{|l|}{ Bilateral vocal cord paralysis } \\
\hline \multicolumn{2}{|l|}{ Cleft palate, micrognathia } \\
\hline \multicolumn{2}{|l|}{ Respiratory distress syndrome } \\
\hline \multicolumn{2}{|l|}{ Right lung hypoplasia (scimitar) } \\
\hline \multicolumn{2}{|l|}{ Gastrointestinal or hepatic } \\
\hline \multicolumn{2}{|l|}{ Heterotaxy without malrotation } \\
\hline \multicolumn{2}{|l|}{ Heterotaxy with malrotation post Ladd procedure } \\
\hline \multicolumn{2}{|l|}{ Gastroschisis } \\
\hline \multicolumn{2}{|l|}{ Anorectal malformation } \\
\hline \multicolumn{2}{|l|}{ Liver hemangiomas } \\
\hline \multicolumn{2}{|l|}{ Genitourinary } \\
\hline \multicolumn{2}{|l|}{ Ambiguous genitalia requiring surgery } \\
\hline \multicolumn{2}{|l|}{ Solitary kidney with hydroureter } \\
\hline \multicolumn{2}{|l|}{ Renal hemangiomas } \\
\hline \multicolumn{2}{|l|}{ Skeletal or vertebral } \\
\hline \multicolumn{2}{|l|}{ Neurologic } \\
\hline \multicolumn{2}{|l|}{ Arnold-Chiari malformation } \\
\hline \multicolumn{2}{|l|}{ Hypoplastic corpus callosum, intracranial cysts } \\
\hline \multicolumn{2}{|l|}{ Factor V Leiden } \\
\hline \multicolumn{2}{|l|}{ Congenital hypothyroidism } \\
\hline \multicolumn{2}{|l|}{ Genetic } \\
\hline Turner syndrome & \\
\hline DiGeorge syndrome & \\
\hline Chromosome 15 microdeletion & \\
\hline Dysmorphic features, unassigned metabolic disorder & \\
\hline
\end{tabular}

Several patients had more than 1 high-risk diagnosis.

this cohort, $28 \%$ of the patients $(45 / 162)$ were considered high risk and $72 \%(117 / 162)$ were considered standard risk. High-risk diagnoses are shown in Table 1. Several patients had multiple high-risk diagnoses. Comparisons of patient characteristics and cardiac diagnostic categories between groups are shown in Table 2. Univentricular lesions other than HLHS, as defined by the International Working Group for Mapping and Coding of Nomenclatures for Paediatric and Congenital Heart Disease, ${ }^{17}$ were more common among high-risk patients $(38 \%, 17 / 45$, vs $15 \%, 18 / 117$, $P=.003$ ). Of the 5 patients with heterotaxy, 1 patient had aortic atresia with mitral atresia, 3 patients had right ventricle-dominant atrioventricular canal, and 1 patient had double-inlet left ventricle.

Intraoperative support times (cardiopulmonary bypass including antegrade cerebral perfusion, circulatory arrest, and total support times) were longer in the high-risk group. Need
TABLE 2. Patient characteristics by risk level

\begin{tabular}{|c|c|c|c|}
\hline & $\begin{array}{c}\text { High } \\
(\mathrm{n}=\mathbf{4 5})\end{array}$ & $\begin{array}{l}\text { Standard } \\
(\mathbf{n}=117)\end{array}$ & $\begin{array}{c}P \\
\text { value }\end{array}$ \\
\hline Birth weight $(\mathrm{kg}$, mean $\pm \mathrm{SD})$ & $2.6 \pm 0.6$ & $3.3 \pm 0.5$ & $<.001$ \\
\hline Gestational age (wk, mean \pm SD) & $37.0 \pm 1.7$ & $38.5 \pm 1.1$ & $<.001$ \\
\hline Sex (no. male) & $23(51 \%)$ & $75(64 \%)$ & .09 \\
\hline Prenatal diagnosis (no.) & $22(49 \%)$ & $69(59 \%)$ & .4 \\
\hline HLHS* (no.) & $28(62 \%)$ & $99(85 \%)$ & .003 \\
\hline Aortic atresia, mitral atresia & $15(33 \%)$ & $51(44 \%)$ & \\
\hline Aortic atresia, mitral stenosis & $1(2 \%)$ & $15(13 \%)$ & \\
\hline Aortic stenosis, mitral stenosis & $12(27 \%)$ & $33(28 \%)$ & \\
\hline Other univentricular lesions (no.) & $17(38 \%)$ & $18(15 \%)$ & \\
\hline \multicolumn{4}{|l|}{ Right ventricle dominant } \\
\hline Unbalanced atrioventricular canal & $4(9 \%)$ & $4(3 \%)$ & \\
\hline $\begin{array}{l}\text { HLHS, ventricular septal defect, } \\
\text { arch obstruction }\end{array}$ & $4(9 \%)$ & 0 & \\
\hline $\begin{array}{l}\text { Double-outlet right ventricle, } \\
\text { mitral atresia }\end{array}$ & $2(4 \%)$ & $3(3 \%)$ & \\
\hline \multicolumn{4}{|l|}{ Left ventricle dominant } \\
\hline Double-inlet left ventricle & $4(9 \%)$ & $3(3 \%)$ & \\
\hline $\begin{array}{l}\text { Tricuspid atresia, transposition } \\
\text { of great arteries }\end{array}$ & $3(7 \%)$ & $8(7 \%)$ & \\
\hline $\begin{array}{l}\text { Ascending aortic diameter } \\
\quad(\mathrm{mm}, \text { mean } \pm \mathrm{SD})\end{array}$ & $4.0 \pm 1.8$ & $3.5 \pm 1.7$ & .1 \\
\hline
\end{tabular}

for postoperative ECMO support within 30 days of S1P was similar between groups: 8 of 45 patients $(18 \%)$ in the highrisk group versus 15 of 117 patients $(13 \%)$ in the standardrisk group. Six patients in each group $(13 \%$ in high-risk group and $5 \%$ in standard-risk group, $P=.095$ ) were placed on ECMO support during the first 24 hours after S1P for catecholamine-resistant shock. No patient in the high-risk group was placed on ECMO for shunt thrombosis, versus 4 patients in the standard-risk group. One additional highrisk patient and 3 standard-risk patients were placed on ECMO for cardiac failure between postoperative days 3 and 15. High-risk patients had longer duration to delayed sternal closure $(7.9 \pm 8.4$ days vs $4.1 \pm 5.5$ days, $P=.002)$ and longer hospital stay (48 \pm 25 days vs $34 \pm$ 15 days, $P<.001$ ).

Operative survival was comparable between groups: 39 of 45 patients $(87 \%)$ in the high-risk group versus 111 of 117 patients $(95 \%)$ in the standard-risk group $(P=.1$; Table 3$)$. Deaths within 30 days of surgery among high-risk patients included a low-birth weight infant with dysmorphic features and an initial attempt at 2-ventricle repair and a second infant with intact atrial septum who underwent atrial septectomy at 1 hour after birth, followed by bilateral pulmonary artery banding on day 5 after birth and S1P on day 15 after birth. These infants died on postoperative days 8 and 29, respectively. The 3 early deaths in the standard-risk group were those of an infant with decreased oral intake while at home on postoperative day 29 , a second infant with shunt 
TABLE 3. Stage 1 palliation operative, postoperative, and interstage variables by risk level

\begin{tabular}{|c|c|c|c|}
\hline & $\begin{array}{c}\text { High } \\
(\mathrm{n}=\mathbf{4 5})\end{array}$ & $\begin{array}{l}\text { Standard } \\
(\mathbf{n}=117)\end{array}$ & $\begin{array}{c}P \\
\text { value }\end{array}$ \\
\hline Age at $\mathrm{S} 1 \mathrm{P}(\mathrm{d}$, mean $\pm \mathrm{SD})$ & $9.3 \pm 6.1$ & $7.2 \pm 6.5$ & .06 \\
\hline Total support time (min, mean \pm SD) & $210 \pm 95$ & $183 \pm 47$ & .04 \\
\hline $\begin{array}{l}\text { Cardiopulmonary bypass } \\
\quad(\min , \text { mean } \pm \mathrm{SD})\end{array}$ & $200 \pm 80$ & $175 \pm 44$ & .02 \\
\hline Circulatory arrest $(\min$, mean $\pm \mathrm{SD}$ ) & $16 \pm 18$ & $10 \pm 5$ & .002 \\
\hline Modified Blalock-Taussig shunt (no.) & $24(53 \%)$ & $84(72 \%)$ & .02 \\
\hline $\begin{array}{l}\text { Time to delayed sternal closure } \\
\qquad(\mathrm{d}, \text { mean } \pm \mathrm{SD})\end{array}$ & $7.9 \pm 8.4$ & $4.1 \pm 5.5$ & .002 \\
\hline $\begin{array}{l}\text { Extracorporeal membrane oxygenation } \\
\text { support within } 30 \mathrm{~d} \text { of S1P (no.) }\end{array}$ & $7(16 \%)$ & $13(11 \%)$ & .6 \\
\hline Operative survival (no.) & $39(87 \%)$ & $111(95 \%)$ & .1 \\
\hline S1P hospital stay $(\mathrm{d}$, mean $\pm \mathrm{SD})$ & $48 \pm 25$ & $34 \pm 15$ & $<.001$ \\
\hline Gastrostomy tube (no.) & $22(49 \%)$ & $38(32 \%)$ & $<.001$ \\
\hline \multicolumn{4}{|l|}{ Interstage management (no.) } \\
\hline Home monitoring & $26(58 \%)$ & $99(85 \%)$ & .001 \\
\hline Interstage event & $17(65 \%)$ & $56(57 \%)$ & .5 \\
\hline Interstage death & 0 & $3(3 \%)$ & $<.999$ \\
\hline Inpatient monitoring & $11(24 \%)$ & $12(10 \%)$ & .001 \\
\hline Transplant & $2(4.4 \%)$ & $3(2.6 \%)$ & .5 \\
\hline Achieved cavopulmonary shunt (no.) & $37(82 \%)$ & $108(92 \%)$ & .08 \\
\hline $\begin{array}{l}\text { Age at cavopulmonary } \\
\text { shunt }(\mathrm{d}, \text { mean } \pm \mathrm{SD})\end{array}$ & $129 \pm 42$ & $114 \pm 34$ & .03 \\
\hline $\begin{array}{l}\text { Weight at cavopulmonary } \\
\text { shunt }(\mathrm{kg}, \text { mean } \pm \mathrm{SD})\end{array}$ & $5.3 \pm 1.4$ & $5.4 \pm 0.9$ & .7 \\
\hline Survival at $1 \mathrm{y}$ (no.) & $35(78 \%)$ & $109(93 \%)$ & .01 \\
\hline Survival to date (no.) & $32(71 \%)$ & $108(92 \%)$ & .001 \\
\hline
\end{tabular}

S1P, Stage 1 palliation.

thrombosis on postoperative day 29 , and a third infant with moderate atrioventricular valve insufficiency during feeding on postoperative day 30 .

S1P with a modified Blalock-Taussig shunt was less common in the high-risk group $(P=.02)$. Shunt type received was not associated with unadjusted outcome in either the high-risk or the standard-risk group (Table 4). After correction for the higher frequency of right ventricle-pulmonary artery conduits in the high-risk group by propensity scoring, there was a reduction in the predicted intermediate survival in the high-risk group (Table 5).

Mortality later than 30 days after S1P but during the same hospitalization consisted of 4 high-risk patients and 3 standard-risk patients. Within the high-risk group, 1 infant with respiratory distress syndrome with an initial attempt at 2-ventricle repair died on ECMO awaiting cardiac transplantation at 11 weeks of age; 1 multiple-gestation infant with respiratory distress syndrome and chronic lung disease died at 10 weeks of age; 1 low-birth weight infant with congenital hypothyroidism died at 11 weeks of age; and 1 infant with heterotaxy, asplenia, and total anomalous pulmonary venous return died at 6 weeks of age. Within the standard-risk group, 1 infant with shunt thrombosis died at age 7 weeks, an infant awaiting transplant died at age 13 weeks, and a third infant
TABLE 4. Unadjusted survival outcomes by shunt type within highrisk and standard-risk groups

\begin{tabular}{|c|c|c|c|}
\hline & $\begin{array}{l}\text { Operative } \\
\text { survival }\end{array}$ & $\begin{array}{l}\text { Survival } \\
\text { at } 1 \mathrm{y}\end{array}$ & $\begin{array}{l}\text { Survival } \\
\text { to date }\end{array}$ \\
\hline \multicolumn{4}{|l|}{ High risk $(n=45)$} \\
\hline $\begin{array}{l}\text { Right ventricle-pulmonary artery } \\
\text { shunt }(\mathrm{n}=24)\end{array}$ & $81 \%$ & $76 \%$ & $67 \%$ \\
\hline $\begin{array}{l}\text { Modified Blalock-Taussig } \\
\quad \text { shunt }(\mathrm{n}=21)\end{array}$ & $92 \%$ & $79 \%$ & $75 \%$ \\
\hline$P$ value & .4 & $>.999$ & .7 \\
\hline \multicolumn{4}{|l|}{ Standard risk $(\mathrm{n}=117)$} \\
\hline $\begin{array}{l}\text { Right ventricle-pulmonary artery } \\
\text { shunt }(\mathrm{n}=33)\end{array}$ & $100 \%$ & $97 \%$ & $94 \%$ \\
\hline $\begin{array}{l}\text { Modified Blalock-Taussig } \\
\text { shunt }(\mathrm{n}=84)\end{array}$ & $93 \%$ & $92 \%$ & $92 \%$ \\
\hline$P$ value & .2 & .4 & .7 \\
\hline
\end{tabular}

died at age 11 weeks on the morning of his scheduled early cavopulmonary shunt for cardiac failure with electrocardiographic evidence of coronary ischemia and coronary ostial stenosis identified on postmortem examination.

Comparisons between groups of early hemodynamics and vasoactive support after S1P are shown in Table 6. Arterial $\mathrm{SaO}_{2}, \mathrm{SvO}_{2}$, arteriovenous oxygen content difference, pulmonary to systemic flow ratio, central venous pressure, and heart rate were similar between high-risk and standard-risk groups. Parameters including mean arterial pressure, $\mathrm{pH}$, base excess, and somatic $\mathrm{SrO}_{2}$ were within targeted ranges for both groups but statistically lower among the high-risk patients than among the standard-risk patients.

High-risk patients were more likely to be managed as inpatients during the interstage period, whereas standard-risk patients were more commonly monitored at home $(P=.001)$. Incidence of breach of home monitoring criteria (a fall in $\mathrm{SaO}_{2}$ or inadequate weight gain) was similar between groups (Table 3).

Thirty-seven of 45 high-risk patients $(82 \%)$ and 108 of 117 standard-risk patients $(92 \%)$ went on to subsequent palliation with a cavopulmonary shunt $(P=.08)$. Weight at cavopulmonary anastomosis was similar between groups; however, high-risk patients underwent cavopulmonary anastomosis at a somewhat older age $(P=.03)$. Two of 45 highrisk patients $(4.4 \%)$ and 3 of 117 standard-risk patients

TABLE 5. Propensity-matched predicted outcomes between risk groups

\begin{tabular}{lcccc}
\hline \multicolumn{1}{c}{ Outcome } & Control & High risk & ATT* & $\boldsymbol{P}$ value \\
\hline Operative survival & $0.98 \pm 0.15$ & $0.83 \pm 0.38$ & $-0.14 \pm 0.08$ & .09 \\
Survival at 1 y & $0.88 \pm 0.32$ & $0.72 \pm 0.46$ & $-0.16 \pm 0.10$ & .09 \\
Survival to date & $0.88 \pm 0.32$ & $0.66 \pm 0.48$ & $-0.22 \pm 0.10$ & .04 \\
\hline
\end{tabular}

$A T T$, Average effect of the treatment on the treated. *The average effect of assignment to high-risk group on outcome is expressed after correction for the propensity to receive a right ventricle-pulmonary artery shunt in each group. There was a significant reduction in predicted outcome in the high-risk group in terms of late survival. 
TABLE 6. Stage 1 palliation postoperative hemodynamics (first 48 hours) by risk level

\begin{tabular}{|c|c|c|c|}
\hline Variable & $\begin{array}{c}\text { High } \\
(n=45)\end{array}$ & $\begin{array}{l}\text { Standard } \\
(\mathbf{n}=117)\end{array}$ & $\begin{array}{c}P \\
\text { value }\end{array}$ \\
\hline Venous $\mathrm{So}_{2}(\%)$ & $62 \pm 9$ & $62 \pm 8$ & .7 \\
\hline Arterial $\mathrm{So}_{2}(\%)$ & $83 \pm 4$ & $83 \pm 4$ & .8 \\
\hline Hemoglobin (mg/dL) & $15.6 \pm 1.5$ & $15.8 \pm 1.5$ & .4 \\
\hline $\begin{array}{l}\text { Arteriovenous oxygen content } \\
\text { difference }(\mathrm{mL} / \mathrm{dL})\end{array}$ & $4.5 \pm 1.8$ & $4.5 \pm 1.6$ & .8 \\
\hline Somatic regional $\mathrm{So}_{2}$ & $74 \pm 8$ & $78 \pm 7$ & $<.009$ \\
\hline Cerebral regional $\mathrm{SO}_{2}$ & $66 \pm 9$ & $67 \pm 8$ & .9 \\
\hline Mean arterial pressure $(\mathrm{mm} \mathrm{Hg})$ & $49 \pm 6$ & $51 \pm 6$ & .01 \\
\hline Central venous pressure $(\mathrm{mm} \mathrm{Hg})$ & $10 \pm 3$ & $10 \pm 2$ & .3 \\
\hline Heart rate (beats/min) & $175 \pm 15$ & $174 \pm 15$ & .3 \\
\hline Pulmonary/systemic blood flow ratio & $1.8 \pm 1.1$ & $1.7 \pm 0.9$ & 6 \\
\hline Inspired oxygen fraction & $0.47 \pm 0.13$ & $0.45 \pm 11$ & .3 \\
\hline $\mathrm{pH}$ & $7.36 \pm 0.08$ & $7.40 \pm 0.08$ & $<.001$ \\
\hline $\mathrm{PCO}_{2}(\mathrm{~mm} \mathrm{Hg})$ & $48 \pm 9$ & $44 \pm 8$ & $<.001$ \\
\hline $\mathrm{PO}_{2}(\mathrm{~mm} \mathrm{Hg})$ & $47 \pm 5$ & $46 \pm 5$ & .3 \\
\hline Base excess (mEq/L) & $0.3 \pm 4.1$ & $1.3 \pm 3.9$ & .02 \\
\hline Systemic VRI & $11.1 \pm 4.7$ & $11.7 \pm 4.4$ & .3 \\
\hline Total pulmonary VRI & $6.9 \pm 2.2$ & $7.6 \pm 2.4$ & .08 \\
\hline Milrinone $(\mu \mathrm{g} /[\mathrm{kg} \cdot \min ])$ & $0.5 \pm 0.2$ & $0.5 \pm 0.1$ & .7 \\
\hline Epinephrine $(\mu \mathrm{g} /[\mathrm{kg} \cdot \mathrm{min}])$ & $0.09 \pm 0.08$ & $0.08 \pm 0.09$ & .13 \\
\hline Norepinephrine $(\mu \mathrm{g} /[\mathrm{kg} \cdot \min ])$ & $0.04 \pm 0.06$ & $0.05 \pm 0.09$ & .5 \\
\hline
\end{tabular}

All data are mean $\pm \mathrm{SD} . \mathrm{SO}_{2}$, Oxygen saturation; $V R I$, vascular resistance index.

(2.6\%) underwent cardiac transplantation rather than cavopulmonary shunt (Table 3). Ages at transplant were similar at $121 \pm 118$ days in the high-risk group and $52 \pm 15$ days in the standard-risk group $(P=.4)$.

After cavopulmonary anastomosis or cardiac transplant and before 1 year of age, there were 4 deaths in the highrisk group and 2 deaths in the standard-risk group. The high-risk group deaths were 2 patients with Turner syndrome, 1 of whom died 2 weeks after takedown of the cavopulmonary shunt and 1 with sepsis who died 5 months after bilateral bidirectional cavopulmonary shunt; a patient with heterotaxy who had an interstage cardiac arrest requiring ECMO and died 7 weeks after cavopulmonary anastomosis with common atrioventricular valvuloplasty; and that of a low-birth weight premature infant with enterovirus myocarditis who died 3.5 months after cavopulmonary shunt. The 2 standard-risk deaths were a patient with interstage cardiac arrest requiring ECMO who died after cavopulmonary anastomosis and atrioventricular valvuloplasty on postoperative day 15 and a patient who died 3 months after cardiac transplant. Overall, 1-year survival $(78 \%$ vs $93 \%$, $P=.01)$ and survival to date $(71 \%$ vs $92 \%, P=.001)$ were lower among high-risk patients than among standardrisk patients (Figure 1).

\section{DISCUSSION}

Previous studies have identified patient-specific risk factors for early mortality after palliation for HLHS and its variants, including prematurity, low birth weight, extracardiac disease, and additional cardiac anomalies. Early survival for these high-risk patients has been reported to be $52 \%$ to $65 \%$, versus approximately $85 \%$ for standard-risk patients. The absolute incremental mortality risk attributable to these identified high-risk patient factors ranges from $15 \%$ to $30 \%{ }^{1,3}$ The point of this study was to assess the effect of our intensive monitoring and goal-directed strategies on the absolute mortality risk attributable to these same patientspecific factors. In the setting of comprehensive monitoring and goal-directed interventions, we observed a lower operative mortality burden associated with high-risk patient-specific factors than previously reported.

During the last decade, we have reported improved early and intermediate survival for patients undergoing Norwood palliation with a monitoring strategy including in-hospital $\mathrm{SvO}_{2}$ measurement and interstage home monitoring of $\mathrm{SaO}_{2}$ and growth velocity. ${ }^{8,9,11,12}$ Furthermore, in a subset of patients from 1996 to 2006 with HLHS, as defined by the International Working Group for Mapping and Coding of Nomenclatures for Paediatric and Congenital Heart Disease, our group reported that no patients with low birth weight, prematurity, or additional extracardiac diagnosis died early after Norwood palliation with the modified Blalock-Taussig shunt, suggesting that perioperative goal-directed therapy may ameliorate the effect of these identified risk factors for mortality. ${ }^{12}$ That report excluded patients who had S1P with right ventricle-pulmonary artery shunt and diagnostic variants of HLHS such as unbalanced atrioventricular canal, a previously reported risk factor for Norwood palliation. ${ }^{18}$

A limitation of this study is the imbalance between groups beyond the predetermined risk factors. In addition to smaller size and younger gestational age, high-risk patients more commonly included variants of HLHS ( $38 \%$ vs $15 \%$ ); however, there was no difference in ascending aorta diameter relative to the standard-risk group. The high-risk group had prolonged intraoperative support times; however, vasoactive support and indices of global oxygen delivery $\left(\mathrm{SvO}_{2}\right.$, arteriovenous oxygen content difference) and cerebral $\mathrm{SrO}_{2}$ were similar between groups. We have previously reported that the impact of perioperative factors on outcome can be successfully minimized with comprehensive monitoring and goal-directed interventions. ${ }^{9,12}$ Although more patients in the high-risk group had S1P with the right ventricle-pulmonary artery conduit, the effect of this difference is not clear. ${ }^{19-22}$ In contrast to findings from the National Heart, Lung, and Blood Institute-sponsored Pediatric Heart Network Single Ventricle Reconstruction Trial, ${ }^{23}$ we did not find a raw survival advantage between shunt types in either risk category. Comparison of the propensity-weighted outcomes between groups to adjust for the imbalance in shunt types between risk groups may indicate an advantage to the right ventricle-pulmonary artery conduit in higherrisk patients. 


\section{Survival Functions}

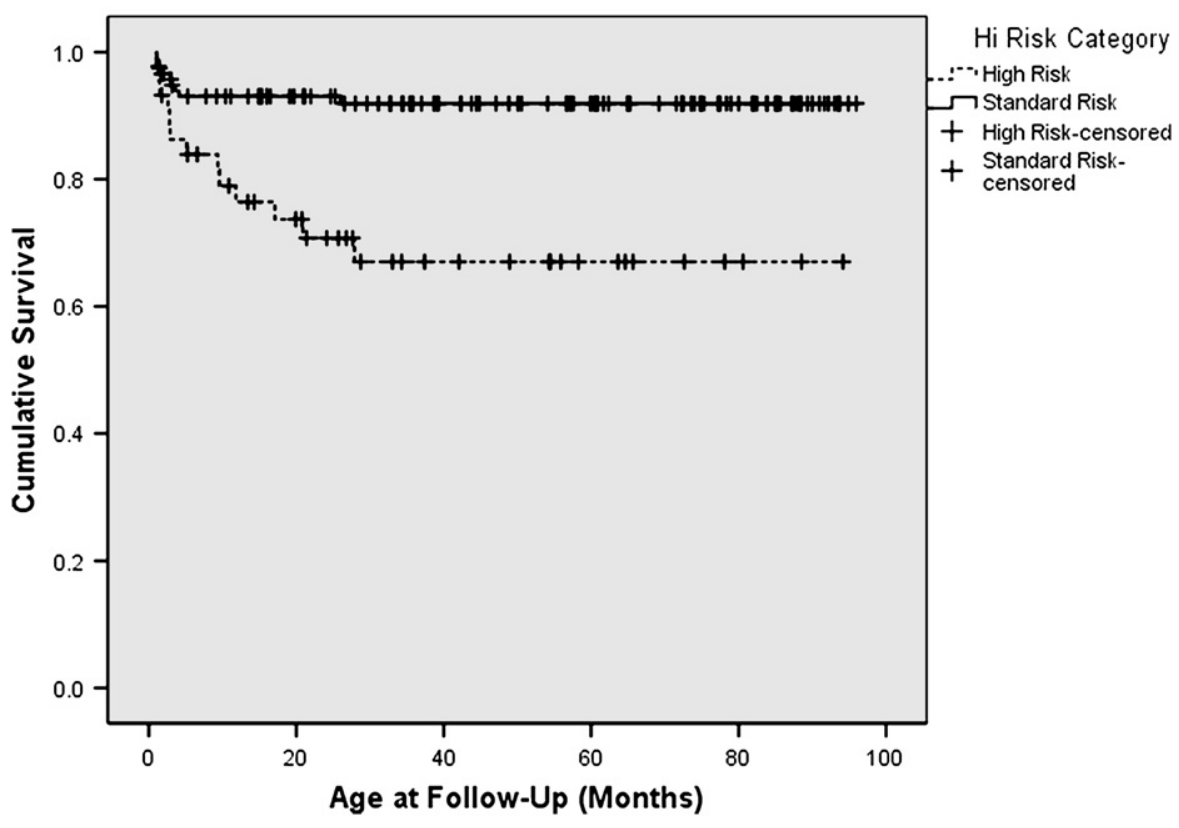

FIGURE 1. Actuarial survivals after Norwood palliation for standard-risk and high-risk patients from September 2000 to September 2008 . Operative survival and survival to cavopulmonary anastomosis are comparable between groups; 1-year survival and survival to date are lower among high-risk patients than among standard-risk patients $(P=.01$ and $P=.001$, respectively).

High-risk patients required more supportive care beyond the early postoperative period. They were more likely to require gastrostomy tube placement for nutritional support and to remain as inpatients until cavopulmonary anastomosis. High-risk patients who underwent cavopulmonary anastomosis were older than standard-risk patients (129 vs 114 days) but were at similar weights at the time of cavopulmonary anastomosis.

Progression to transplant after S1P was similar between risk groups. Because transplant is an acceptable alternative strategy anytime during progression to and beyond Fontan palliation, we did not equate transplant with death but rather separated these outcomes. Patients listed for transplant were considered to be the most fragile and poorest candidates for cavopulmonary connection on the basis of anatomic or physiologic vulnerabilities identified during the perioperative period. These patients also represented a subset considered to be at greatest risk for death after initial palliation. Survival to transplant thus may be considered a successful result of comprehensive perioperative monitoring and goal-directed interventions as routine adjuncts to therapies. Nonetheless, the early outcomes between groups were not different when both transplant and death were counted as failures.

One patient in each group died within 30 days after cavopulmonary anastomosis. Death beyond the early postcavopulmonary anastomosis period was a feature of the high-risk group, with 3 patients dying in this interval. Survival among the high-risk patients were significantly lower than those among standard-risk patients both at 1 year
(78\% vs $92 \%$ ) and to date ( $72 \%$ vs $92 \%$; Figure 1). These results suggest that as long as high-risk patients are subject to heightened surveillance, similar early survival to that of standard-risk patients is possible. Although standard-risk patients enjoy a period of relative lower risk after cavopulmonary anastomosis, this period of relative safety does not appear to extend to high-risk patients. To achieve results comparable with those of standard-risk patients, continued monitoring or alternative therapy such as heart transplant should be considered for high-risk patients on a case-bycase basis. Although long-term survival will likely continue to be lower for some patient groups, such as those with Turner syndrome, these data suggest that the outcome of the high-risk group is not fixed but instead can be improved with continued higher intensity monitoring.

\section{CONCLUSIONS}

With an intensive monitoring strategy, comparable early survival was achieved for these patient risk strata. Early goal-directed treatment of shock has demonstrated survival value in a wide variety of patients, and the neonatal cardiac patient is no exception. The therapeutic benefit of a comprehensive goal-directed hemodynamic monitoring and treatment strategy is not lost on high-risk cardiac patients, and the outcomes achieved with this approach exceed previous published outcomes.

We thank Robert D. B. Jaquiss, MD, for his contribution in program development and management of this cohort. 


\section{References}

1. Gaynor JW, Mahle WT, Cohen MI, Ittenbach RF, DeCampli WM, Steven JM, et al. Risk factors for mortality after the Norwood procedure. Eur J Cardiothorac Surg. 2002;22:82-9.

2. Pizarro C, Davis DA, Galantowicz ME, Munro H, Gidding SS, Norwood WI. Stage I palliation for hypoplastic left heart syndrome in low birth weight neonates: can we justify it? Eur J Cardiothorac Surg. 2002;21:716-20.

3. Stasik CN, Gelehrter S, Goldberg CS, Bove EL, Devaney EJ, Ohye RG. Current outcomes and risk factors for the Norwood procedure. J Thorac Cardiovasc Surg. 2006;131:412-7.

4. Artrip JH, Campbell DN, Ivy DD, Almodovar MC, Chan KC, Mitchell MB, et al. Birth weight and complexity are significant factors for the management of hypoplastic left heart syndrome. Ann Thorac Surg. 2006;82:1252-9.

5. Jacobs JP, O'Brien SM, Chai PJ, Morell VO, Lindberg HL, Quintessenza JA. Management of 239 patients with hypoplastic left heart syndrome and related malformations from 1993 to 2007. Ann Thorac Surg. 2008;85:1691-7.

6. Pizarro C, Murdison KA, Derby CD, Radtke W. Stage II reconstruction after hybrid palliation for high-risk patients with a single ventricle. Ann Thorac Surg. 2008;85:1382-8.

7. Sano S, Ishino K, Kawada M, Arai S, Kasahara S, Asai T, et al. Right ventriclepulmonary artery shunt in first-stage palliation of hypoplastic left heart syndrome. J Thorac Cardiovasc Surg. 2003;126:504-10.

8. Ghanayem NS, Hoffman GM, Mussatto KA, Cava JR, Frommelt PC, Rudd NA, et al. Home surveillance program prevents interstage mortality after the Norwood procedure. J Thorac Cardiovasc Surg. 2003;126:1367-77.

9. Tweddell JS, Hoffman GM, Mussatto KA, Fedderly RT, Berger S, Jaquiss RD, et al. Improved survival of patients undergoing palliation of hypoplastic left heart syndrome: lessons learned from 115 consecutive patients. Circulation. 2002; 106(12 Suppl. 1):I82-9.

10. De Oliveira NC, Ashburn DA, Khalid F, Burkhart HM, Adatia IT, Holtby HM, et al. Prevention of early sudden circulatory collapse after the Norwood operation. Circulation. 2004;110(11 Suppl. 1):II133-8.

11. Ghanayem NS, Tweddell JS, Hoffman GM, Mussatto K, Jaquiss RD. Optimal timing of the second stage of palliation for hypoplastic left heart syndrome facilitated through home monitoring, and the results of early cavopulmonary anastomosis. Cardiol Young. 2006;16(Suppl. 1):61-6.

12. Tweddell JS, Ghanayem NS, Mussatto KA, Mitchell ME, Lamers LJ, Musa NL, et al. Mixed venous oxygen saturation monitoring after stage 1 palliation for hypoplastic left heart syndrome. Ann Thorac Surg. 2007;84:1301-11.
13. Li J, Zhang G, McCrindle BW, Holtby H, Humpl T, Cai S, et al. Profiles of hemodynamics and oxygen transport derived by using continuous measured oxygen consumption after the Norwood procedure. J Thorac Cardiovasc Surg. 2007; 133:441-8

14. Tweddell JS. The Norwood procedure with an innominate artery-to-pulmonary artery shunt. In: Operative techniques in thoracic and cardiovascular surgery: a comparative atlas. 2005; 10:123-40.

15. Tweddell JS, Hoffman GM, Fedderly RT, Berger S, Thomas JP Jr, Ghanayem NS, et al. Phenoxybenzamine improves systemic oxygen delivery after the Norwood procedure. Ann Thorac Surg. 1999;67:161-8.

16. Jaquiss RD, Ghanayem NS, Hoffman GM, Fedderly RT, Cava JR, Mussatto KA et al. Early cavopulmonary anastomosis in very young infants after the Norwood procedure: impact on oxygenation, resource utilization, and mortality. $J$ Thorac Cardiovasc Surg. 2004;127:982-9.

17. Tchervenkov CI, Jacobs JP, Weinberg PM, Aiello VD, Beland MJ, Colan SD, et al. The nomenclature, definition and classification of hypoplastic left heart syndrome. Cardiol Young. 2006;16:339-68.

18. Owens GE, Gomez-Fifer C, Gelehrter S, Owens ST. Outcomes for patient with unbalanced atrioventricular septal defects. Pediatr Cardiol. 2009;30: 431-5.

19. Tabbutt S, Dominguez TE, Ravishankar C, Marino BS, Gruber PJ, Wernovsky G et al. Outcomes after the stage I reconstruction comparing the right ventricular to pulmonary artery conduit with the modified Blalock Taussig shunt. Ann Thorac Surg. 2005;80:1582-91.

20. Bradley SM, Simsic JM, McQuinn TC, Habib DM, Shirali GS, Atz AM. Hemodynamic status after the Norwood procedure: a comparison of right ventricleto-pulmonary artery connection versus modified Blalock-Taussig shunt. Ann Thorac Surg. 2004;78:933-41.

21. Mahle WT, Cuadrado AR, Tam VK. Early experience with a modified Norwood procedure using right ventricle to pulmonary artery conduit. Ann Thorac Surg. 2003;76:1084-9.

22. Azakie A, Martinez D, Sapru A, Fineman J, Teitel D, Karl TR. Impact of right ventricle to pulmonary artery conduit on outcome of the modified Norwood procedure. Ann Thorac Surg. 2004;77:1727-33.

23. Ohye RG, Tabbutt S, Sleeper LA, Pearson GD, Mahoney L, Newburger JW, et al. Outcomes of the Norwood operation in infants randomized to a modified BlalockTaussig versus right ventricle to pulmonary artery shunt: The Pediatric Heart Network Single Ventricle Reconstruction Trial [abstract]. Circulation. 2009; 120:S560. 